\title{
Energy recovery from natural gas pressure reduction stations: Integration with low temperature heat sources
}

\author{
Davide Borelli ${ }^{1}$, Francesco Devia ${ }^{1}$, Ermanno Lo Cascio ${ }^{1}$, Corrado Schenone ${ }^{*}, 1$ \\ DIME - Dipartimento di Ingegneria Meccanica, Energetica, Gestionale e dei Trasporti, Università degli Studi di Genova, Via All'Opera Pia 15/A, 16145 Genova, Italy
}

\section{ART ICLE INFO}

\section{Keywords:}

Natural gas networks

Pressure reduction stations

Energy recovery

Networks integration

Methane hydrate formation

Low temperature heat sources

\begin{abstract}
A B S T R A C T
Energy recovery from Natural Gas (NG) distribution networks is a promising strategy in order to pursue energy sustainability in urban areas. The NG pressure reduction process, normally achieved by means of conventional throttling valves, can be upgraded by implementing turbo expander technology, which allows recovery of energy from the NG pressure drop. As commonly known, in this process the NG must be preheated in order to avoid methane-hydrate formation. The preheating temperature represents a key parameter of the process, on which depends the possibility of integrating low enthalpy heat sources into the system and of exploiting more efficient technologies and renewable energies as well. In this work, the possibility of integrating a pressure reduction station with low temperature heat sources is studied. In particular, a novel plant configuration consisting of a two-stage expansion system is presented and its energy performances are investigated by means of numerical dynamic simulations. The risk of formation of methane hydrate is assessed for different operating conditions and for transient behavior. Finally, the energy efficiency of PRSs with high and low temperature configuration is compared, showing how the two stage expansion can achieve higher energy performance and be effectively integrated with low enthalpy heat sources.
\end{abstract}

\section{Introduction}

The European Union is strongly committed to policies for energy sustainability and Waste Energy Recovery (WER) in urban areas [1]. Natural Gas (NG) networks are a promising opportunity for widespread energy recovery in cities. The large extension of NG grids and the high number of NG Pressure Reduction Stations (PRS) present in the European territory allows the pursuit of an effective strategy to exploit the pressure drop from transportation pipelines to local networks, which is currently dissipated in expansion valves [2], converting this otherwise wasted mechanical energy into electricity by means of expanders (from here on, the WER acronym will refer to this kind of energetic conversion). For instance, there are about 416 PRS in Spain [2], while Austria and Denmark count about 40 main PRS each $[3,4]$. Moreover, a continuously increasing trend can be noticed inside and outside the EU, with a growing extension of the NG network and, correspondingly, of the number of PRS. In Turkey the number of PRS rose from 274 in 2010 to 320 in 2012 [5]. Therefore, there is a large WER potential in NG transmission grids, since from each station a non-negligible amount of en- ergy can be recovered. Borelli et al. [6], for a given case study in Italy, estimated a potential WER of about $2.9 \mathrm{GWh}$ /year for a total preheating need of about $3.1 \mathrm{GWh}$ /year. Alparslan et al. [5] instead, estimated a potential WER of about $4.11 \mathrm{GWh} /$ year for a maximum of $6.36 \mathrm{GWh} /$ year of thermal preheating energy. Mansoor and Mansoor [7] defined an action program for WER in Bangladesh. Other examples of TE application can be found in Kostowski [8]. In this study, the system efficiency is about $60 \%$ and, according to the authors, positive economic results could be achieved with appropriate system design. The case study relative to the Khangiran refinery was presented by Farzaneh-gord in [9]. Here, the plant is capable of delivering a high amount of NG of about $390 \mathrm{~kg} / \mathrm{s}$. For this purpose, the electricity generation is designed to be about 7.5 MW which surely generates a non-negligible WER potential.

However, this option for energy recovery is not so obvious as might appear, since hard operating limits arise from the thermodynamic process happening when NG expands. In fact, for PRS functioning it is fundamental to maintain NG temperature above a certain threshold in order to avoid the formation of methane hydrates. These are solid com-

\footnotetext{
* Corresponding author.

Email address: corrado.schenone@unige.it (C. Schenone)

1 All authors contributed equally to the work.
} 
pounds, resembling snow or ice in appearance and are formed with methane, ethane, propane, and isobutane in the presence of water at elevated pressures and temperature [10]. A description of the methane-hydrate formation mechanism was supplied by Koh et al. [11]. Ashouri et al. [12] calculated the minimum NG temperature at the inlet of throttling valves enabling avoidance of the formation of a solid phase. Among the methane-hydrate predictive models available in the literature, Khamehchi et al. [13] proposed a relevant predictive neural network model based on 356 experimental data.

This issue has traditionally limited energy recovery from PRS since the NG needs to be preheated before the expansion in order to produce electricity. This problem is usually solved by providing heat with a boiler or, in a better configuration, with a Combined Heat Production (CHP) system $[14,15]$. Recently, a more advanced solution was proposed, which considers the actual expansion ratio $\beta$ for NG in city gate stations [16]. As reported in [17], the typical $\beta$ value is almost 5 but, in some cases, $\beta$ ranges from 8 to 12 , up to a maximum of 15 . Some of these characteristic operating ratios enable the possibility of splitting the expansion process into two stages, and allows lowering the overall process temperature. In this way, due to the typical pressure operating ranges and geographical positioning, energy recovery from PRS represents a key opportunity for eco-industrial park development [18] and low temperature thermal process integration e.g. industrial micro-grid networks [19] and 4th generation district heating networks [20] whose typical operating temperatures are about $50{ }^{\circ} \mathrm{C}$. Moreover, the opportunity to lower the temperature enables the possibility of employing a wider range of heat production technologies, such as geothermal heat pumps or thermal solar panels [21-23], CHP, sewage water assisted heat pumps, heat pumps assisted from waste heat from manned spaces (e.g. underground air ventilation of waste air ventilation of big malls) whose usual supply temperatures currently range from 40 to $85^{\circ} \mathrm{C}$ [20].

In general, the integration with district heating networks or waste heat sources in urban areas offers a noticeable opportunity for coupled energy recovery. Moreover, PRS operating schedule is directly linked to the NG users' demand, which leads to a spontaneous load matching between heating supply and demand in buildings, thus making the integration between PRS and district heating networks even more favorable. This integration of NG network with urban thermal grids, as well as the exploitation of a part of the large waste heat amount available inside cities, is a smart opportunity to improve urban energy recovery and to achieve a more effective energy use.

However, this smart and novel technology for diffused energy saving requires a further step in terms of system analysis and modeling, since the management of the low temperature heat coming from DHN or WER needs the plant to be adapted and controlled in a new way compared to the common integration with a CHP system. The purpose of this work is precisely to study the integration of PRS with low temperature heat sources. Energy performance of a typical low temperature PRS configuration was analyzed though numerical dynamic simulations. The results were compared to high temperature ones and energy benefits were estimated for a typical winter day. Furthermore, time-to-hydrates was assessed by considering the analytical predictive formulations of Motiee et al. [24], Mokhatab et al. [25] and Kidnay et al. [26].

\section{System configurations}

At first glance, energy recovery from gas expansion seems to involve positive aspects only, and a large diffusion could be expected. Nevertheless, only few plants are currently in operation. Enthusiasm for this technological solution often collides with technical constraints and economic problems, mainly due to two different needs: guarantee- ing safety when manipulatıng a rrammadie substance and preneating the gas, thus consuming fuel. Therefore, this kind of energy recovery system becomes less convenient not only from an energy viewpoint, but even from operating and economic ones. The opportunity to reuse waste energy or exploit existing heat facilities can move the balance towards a more efficient utilization of the NG pressure drop, fostering in this way the diffusion of expansion technology. In this sense, research on integrating low temperature heat sources in the PRS energy recovery systems is a key issue, which deserves to be deepened and analyzed well.

One of the constraints that one must face in designing an energy recovery system based on NG pressure drop is methane-hydrate formation. Solidification of methane hydrates occurs when water molecules form a cage-like structure around smaller guest molecules (e.g. methane, ethane, propane, isobutane, normal butane, nitrogen, carbon dioxide, and hydrogen sulfide) [27]. Many studies have focused on methane-hydrate formation in natural gas pipelines. Considering the NG composition shown in Table 1 and a pressure of about 5 bar, three different mathematical correlations have been considered in order to identify methane-hydrate formation temperature. More precisely, by considering the correlations of Motiee et al. [24], Mokhatab et al. [25] and Kidnay et al. [26], methane-hydrate formation respectively occurs at temperatures of about $-4.5^{\circ} \mathrm{C},-2.7^{\circ} \mathrm{C}$ and $-2.2^{\circ} \mathrm{C}$.

In general, this is a very challenging limit. Nevertheless, in urban areas or wherever possible, when properly managed it does not reduce the possibility of integrating a DHN or even an industrial waste energy source with the PRS to recover waste heat (also at low temperatures) in order to reach a higher level of efficiency.

However, it must be noticed that integration between the TE, which generates electricity from NG expansion, and the low temperature heater requires the adaptation of the system configuration in order to optimize its functioning and, ultimately, its control. For the purpose of analyzing the system behavior for different operating conditions and to find an effective set-up, two different plant configurations were analyzed and compared. A traditional set-up was studied, with a single TE like the one installed in the city of Genoa within the framework of the EU project CELSIUS (Combined Efficient Large Scale Integrated Urban Systems) [1], hereafter called "GE1 demonstrator" (Fig. 1). Then a low temperature integrated system was modeled. The GE1 demonstrator consists of a TE, capable of delivering a nominal power of $550 \mathrm{~kW}_{\mathrm{e}}$, whose design working flow rate is $22500 \mathrm{Sm}^{3} / \mathrm{h}$, a slightly lower value than the average hourly flow rate of the PRS. The TE processes the NG from the national transport network, at a pressure of $24 \mathrm{bar}_{\mathrm{g}}$, reducing its pressure to 5 bar $_{\mathrm{g}}$.

Fig. 1 shows pictures of GE1 demonstrator, while Fig. 2 presents a simplified schematization of High and Low Temperature PRS Configurations, named respectively HTC and LTC: in brief, low temperature refers to two-stage expansion whereas high temperature refers to a single expander. In the high temperature configuration (Fig. 2a), the NG is

Table 1

NG composition at standard conditions $\left(15^{\circ} \mathrm{C}\right.$ and $\left.1 \mathrm{~atm}\right)$ [15].

\begin{tabular}{ll}
\hline Chemical substance & Weight composition [\%] \\
\hline Methane & 92.347 \\
Ethane & 4.646 \\
Carbon dioxide & 0.568 \\
Normal butane & 0.133 \\
Isobutane & 0.102 \\
Pentane & 0.031 \\
Isopentane & 0.028 \\
Helium & 0.017 \\
Propane & 0.8 \\
Nitrogen & 1.319 \\
Other hydrocarbons & 0.009 \\
\hline
\end{tabular}




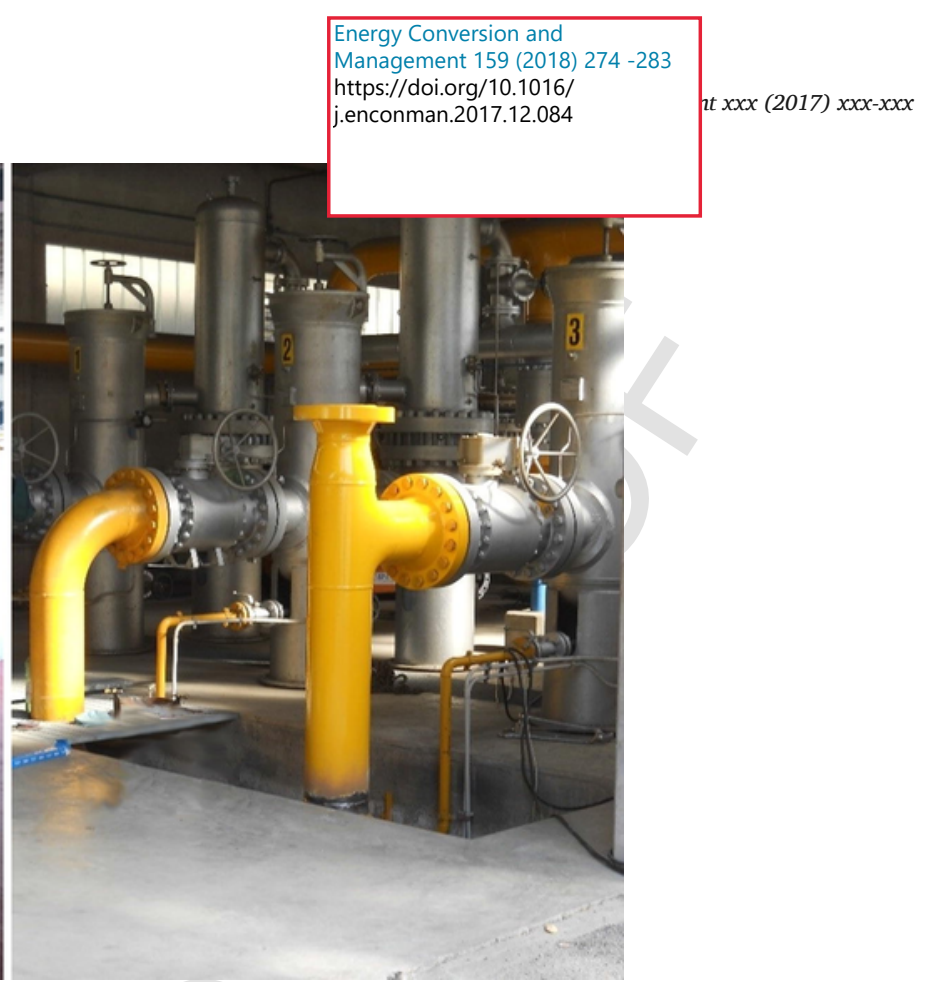

Fig. 1. GE1 demonstrator (left: turboexpander; right: throttling valves).

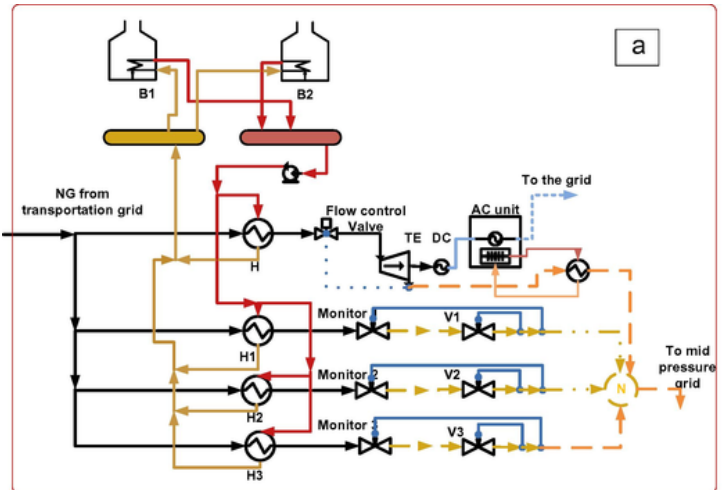

High pressure NG

$\stackrel{\text { Hot water }}{\longrightarrow}$ Returning water

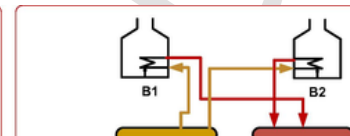

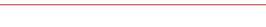

b

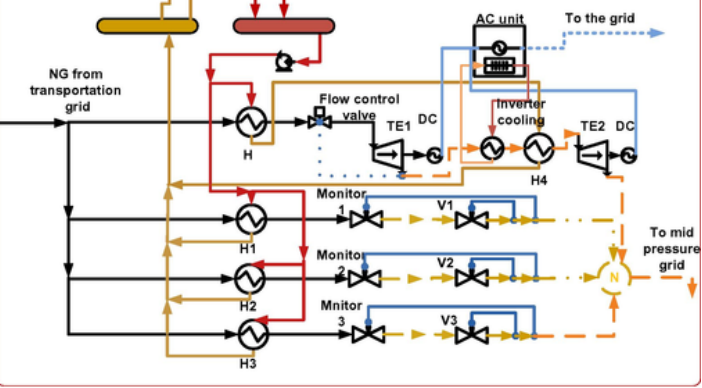

Medium pressure TE pressure NG grid

controller

Throttling valve pressure controller

Fig. 2. System configuration: (a) high temperature - HTC; (b) low temperature - LTC.

preheated with a process water temperature of about $85^{\circ} \mathrm{C}$ by means of a shell and pipe heat exchanger $(\mathrm{H})$. The thermal energy is provided by means of two, standard, gas-fired boilers, which produce the hot water necessary to accomplish the NG preheating process. Referring to the low temperature configuration (Fig. 2b), the gas expands in two TEs in series and the process temperature is lower [28-31]. In this way, since the total NG pressure drop is split into two stages, the thermal preheating need at each expansion is lower. Also in this case, as described for the high temperature configuration, the NG is used as a vector for the AC unit cooling process. Referring to TE sizes and geometry, for the case study considered, the mass flow rate through the TEs are the same for both system configurations. For both HTC and LTC, looking upstream of the TEs, there is a flow control valve that enables NG mass flow regulation. A single-phase Direct Current (DC) generator converts the mechanical power into electricity, that is consequently transformed into Alternating Current (AC) by means of an inverter. The AC is cooled by the cold NG, which comes from the TE. This arrangement has the dual benefit of cooling the AC and helping to prevent the formation of hydrates in the NG stream. Along the conventional expansion lines, for both HTC and LTC, each throttling valve (V1, V2 and V3 in Fig. 2) is provided with a twin one called "monitor", whose purpose is to lock the line in case of downstream fault. Here, the preheating process is achieved by means of shell and pipes heat exchangers as well (H1, H2 and $\mathrm{H} 3$ in Fig. 2).

\section{Numerical model setup}

The two previously described configurations were numerically modeled by means of Honeywell UniSim Design Suite ${ }^{\circledR}$ software [32]. The UniSim model simulations were based on Peng-Robingson state equations for NG. The mathematical modeling of the components is based on UniSim Design ${ }^{\circledR}$ features, which use the implicit fixed step size Euler method [33] embedded in the software to solve the equations that describe the dynamic behavior of a lumped parameters model. Fig. 2 shows the sketch of the High Temperature Configuration, on the left (a), and the one of the novel Low Temperature Configuration, on the right (b). For both cases, the NG inlet temperature and pressure were set at $15^{\circ} \mathrm{C}$ and 25 bar with an expansion ratio of about 5 respectively, which is, as mentioned in the previous section, the most typical operating condition for NG distribution for PRSs located in urban areas. Heat 
3.2. Low temperature confi $\mid$\begin{tabular}{l|}
\hline $\begin{array}{l}\text { Energy Conversion and } \\
\text { Management } 159 \text { (2018) 274- } \\
283 \\
\text { https://doi.org/10.1016/ }\end{array} \mid x x$ (2017) $x x x$-enconman.2017.12.084 \\
\hline
\end{tabular}

In the low temperature comrguration, ure tirotumg-valve-control logic is defined similarly to the one used for the high temperature configuration. However, in this case two TEs will be implemented in series in order to split the NG expansion process into two stages. For this purpose, an intermediate pressure that maximizes the specific work of the entire expansion process has been used. As described in Table 2, this corresponds to 11 bar.

\section{System transient analysis}

In the following sections, numerical results of the above mentioned high- and low-pressure system configuration are presented. Both configurations were studied in dynamic regime for different NG flow scenarios and boundary conditions. A typical winter-day NG flow scenario was analyzed in order to identify the main parameters of the process: TE energy production and outlet NG pressure and temperature, thermal energy needs and boilers' dynamic behavior and, consequently, throttling valves' dynamic response. This critical NG flow scenario was selected due to its particular trend and peaks, because, among all NG possible flows which take place over a year, it allows us to observe the TEs and throttling-valve parallel operation. In fact, by considering typical summer NG-flow scenarios, it might be possible not to see the dynamic behavior of the throttling valves due to the lower NG volume flows involved.

The selection of one-day load profile was made in line with the concept of "average intense day", which consists in calculating the NG mass flow rate as an average of a group of winter days in which the NG mass flow rates are the highest. This procedure is aimed to the selection of a typical winter day, which is characterized by relevant variations load of NG flow rate, and not the worst one in which all the components work steadily at the maximum of their respective capabilities.

Anyway, even if the analyzed systems represent particular cases, sometimes extreme, the outcome has a general value and obtained results lead to overall conclusions, so that the current study may guide researchers and technicians facing the same issues.

\subsection{High temperature configuration}

Fig. 4 shows a typical winter-day NG flow scenario and Fig. 5 depicts the corresponding TE power production. As shown in Fig. 6, the TE's NG inlet and outlet temperature are stable at values of about $71^{\circ} \mathrm{C}$ and $5{ }^{\circ} \mathrm{C}$ respectively, with slight differences in transient phases that do not affect system safety and operation. The same consideration is valid for the TE's NG pressures in Fig. 7. For the same NG-flow scenario, during NG demand peaks, the boilers will achieve a thermal power output of about $800 \mathrm{~kW}_{\mathrm{t}}$ as shown in Fig. 8. Finally, referring to Fig. 9, as described in the previous section, each valve, V1, V2 and V3, will proportionally open depending on the NG mass flow with sequential dynamics. Valve-outlet temperatures are shown in Fig. 10. The water flows for the preheating process are about 40 and 60 cubic meters per hour for TE and valves lines respectively.

\subsection{Low temperature configuration}

Model set points.

\begin{tabular}{|c|c|c|c|c|c|}
\hline Configuration & $\begin{array}{l}\mathrm{TE} \\
(\mathrm{kPa})\end{array}$ & $\begin{array}{l}\text { 2nd } \\
\text { TE } \\
(\mathrm{kPa})\end{array}$ & $\begin{array}{l}\mathrm{V} 1 \\
(\mathrm{kPa})\end{array}$ & $\begin{array}{l}\mathrm{V} 2 \\
(\mathrm{kPa})\end{array}$ & $\begin{array}{l}\text { V3 } \\
\text { (kPa) }\end{array}$ \\
\hline High temp. & 560 & - & 500 & 450 & 400 \\
\hline Low temp. & 1100 & 520 & 500 & 450 & 400 \\
\hline
\end{tabular}

The same NG-flow scenario as Fig. 4 was simulated for the PRS low temperature configuration. In this case, process-water-temperature set point was set to $55^{\circ} \mathrm{C}$ for boilers. The pressure set point is designed to give priority to the recovery line i.e. the highest set point is implemented in the TE and following valves will sequentially open as happens for the high temperature configuration. The results for TE's me- 


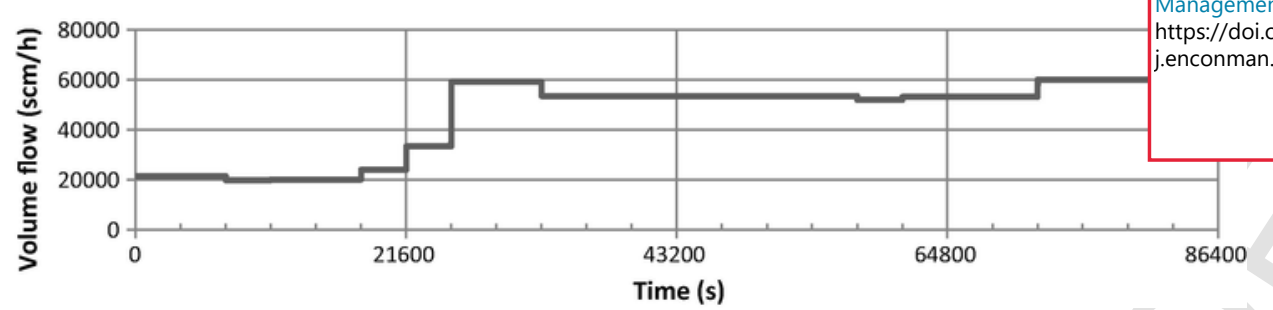

Fig. 4. NG standard daily flow scenario.

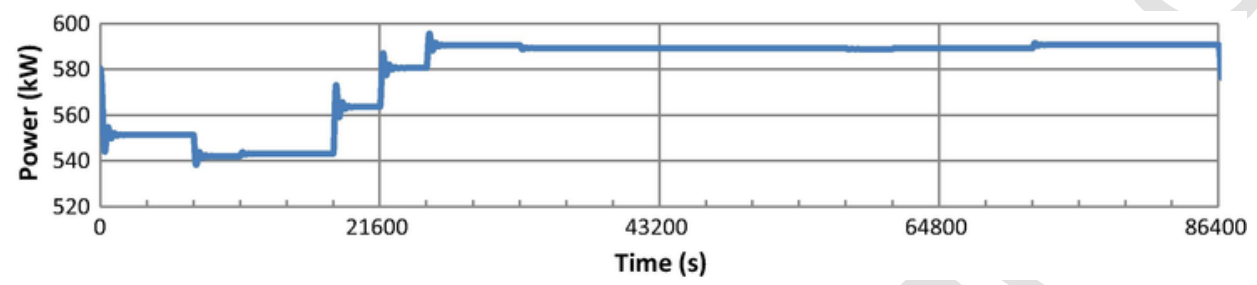

Fig. 5. TE mechanical power production.

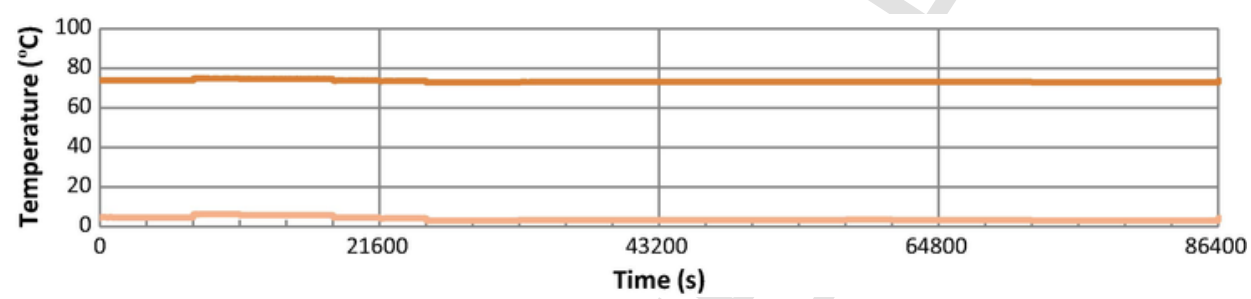

Fig. 6. TE, NG inlet and outlet temperatures.

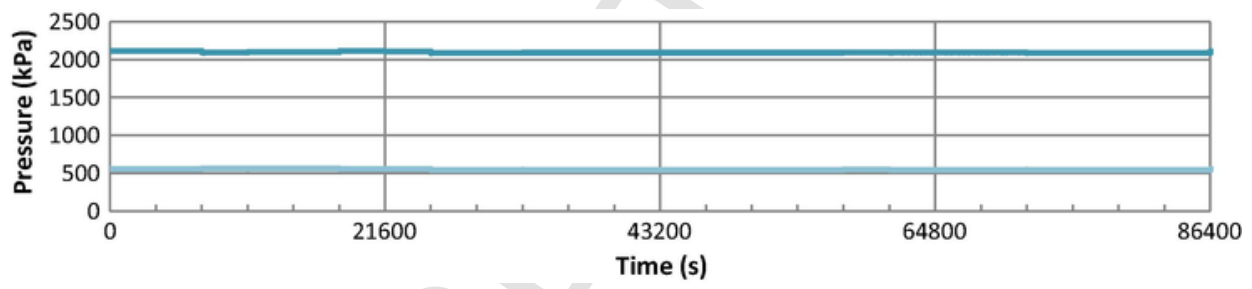

Fig. 7. TE, NG inlet and outlet pressures.

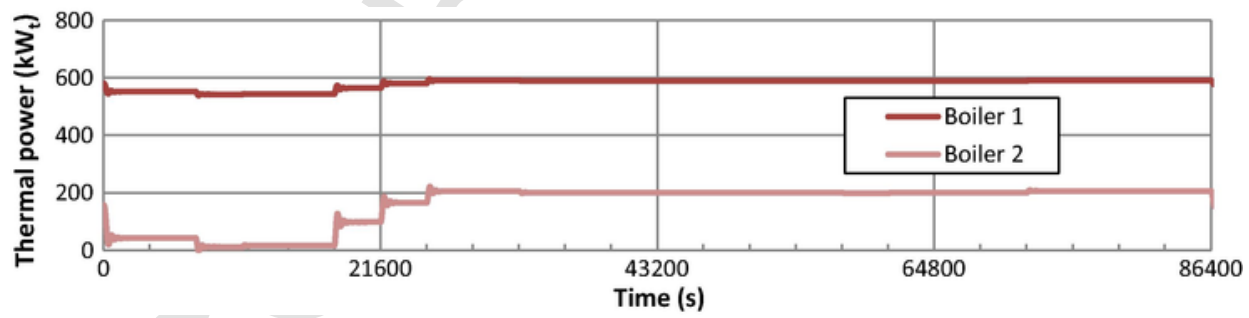

Fig. 8. Boilers' thermal production.

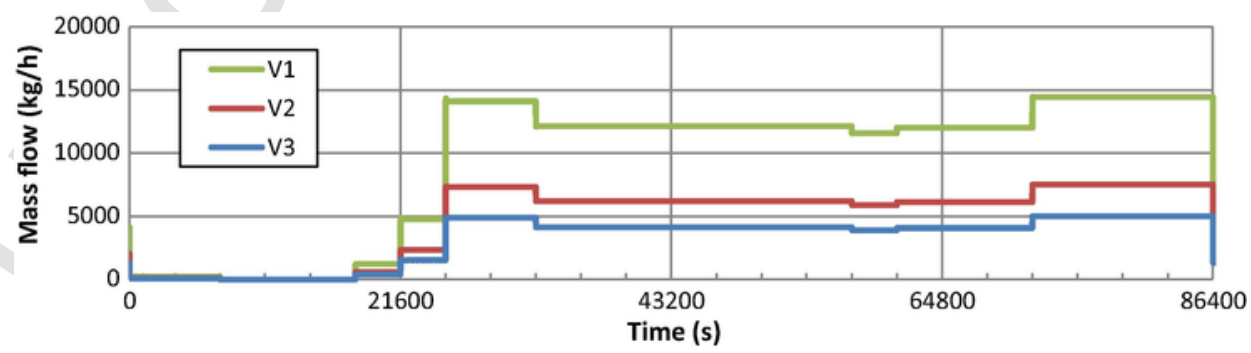

Fig. 9. Throttling valves, NG mass flows. 


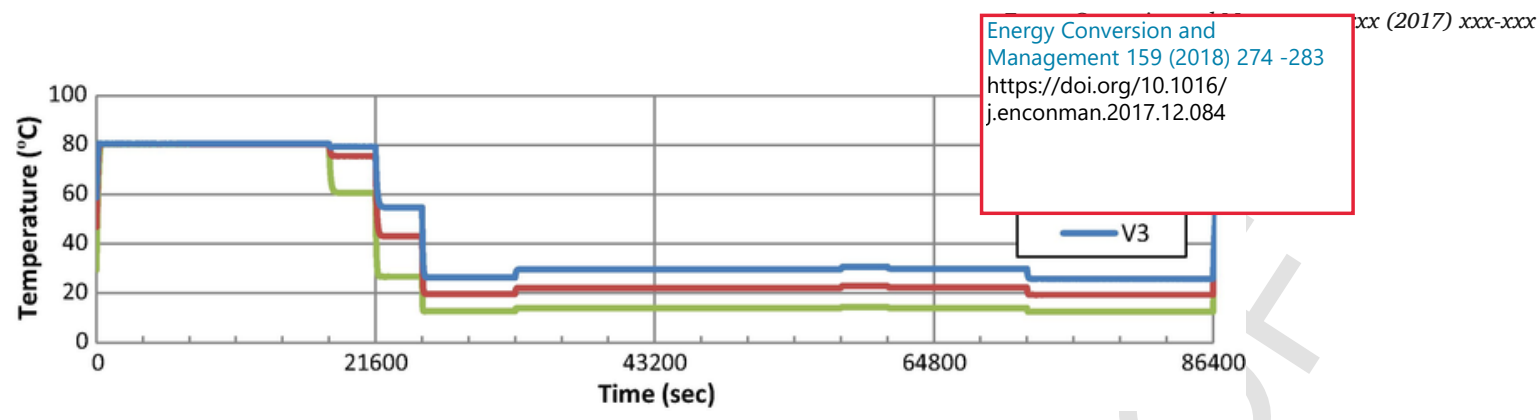

Fig. 10. Throttling valves, NG outlet temperatures.

chanical power are shown in Fig. 11. It is possible to observe that, with the selected intermediate pressure, power generation is almost equally subdivided in both the first and second stages. Fig. 12 shows the effect of the transient phases on the first and second stage TE outlet pressures. Here it is possible to appreciate that the NG pressure regulation is performed with high stability even when NG flow transients occur. Instead, Fig. 13 presents the outlet temperatures at the first stage and at the second stage of the TEs. Referring to Fig. 14, during NG demand peaks, the two boilers will achieve a thermal power output of about
$650 \mathrm{~kW}_{\mathrm{t}}$. As modeled for the high temperature configuration, the preheating-process-water flows are about 40 and 60 cubic meters per hour for TE and valve lines respectively. Finally, Figs. 15 and 16, show the throttling valves' NG mass flow and outlet temperatures respectively.

\subsection{Time-to-hydrates}

The set of conditions introduced in Section 2, that is 5 bar as output pressure and $15^{\circ} \mathrm{C}$ as inlet temperature, was used as a reference base

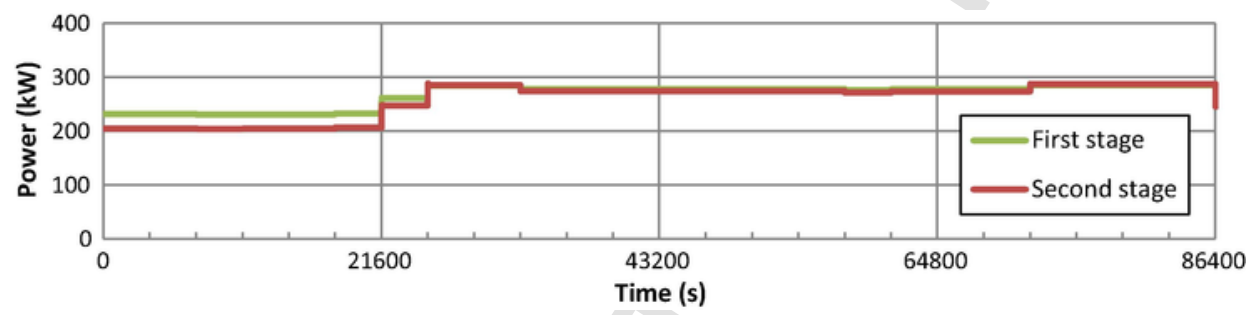

Fig. 11. TEs mechanical power production.

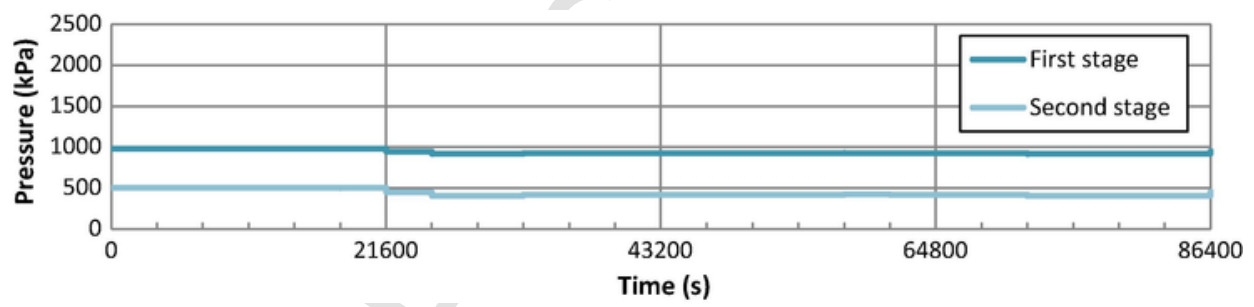

Fig. 12. TEs, NG outlet pressures.

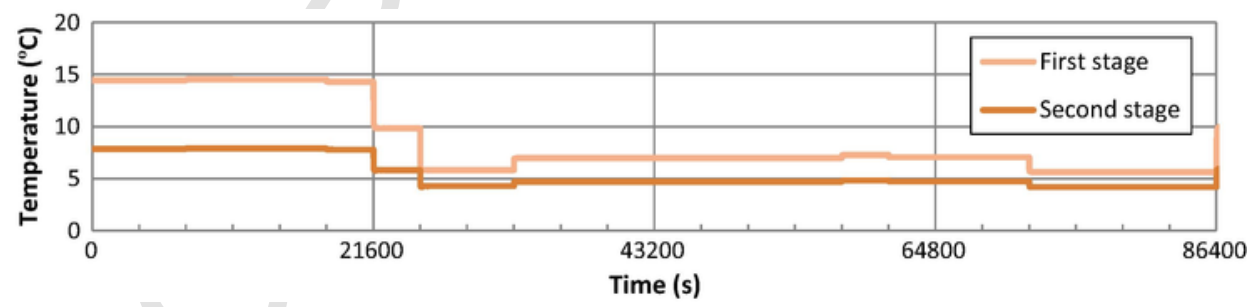

Fig. 13. TEs, NG outlet temperatures.

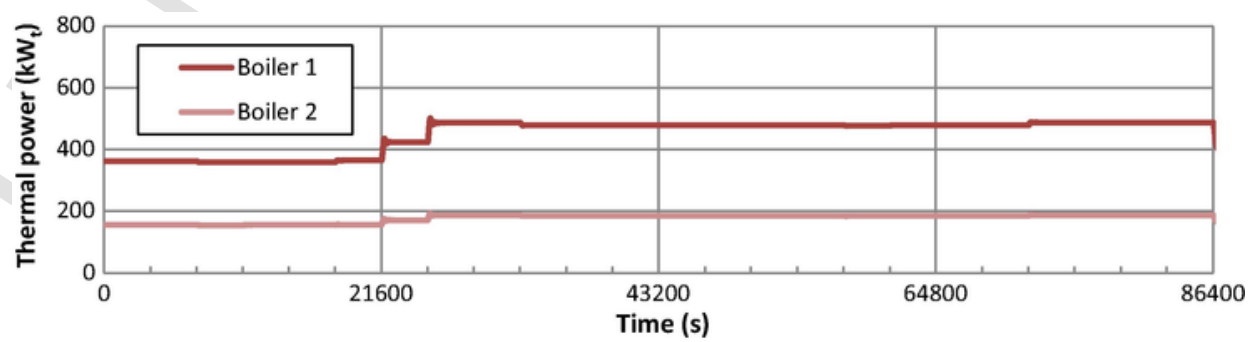

Fig. 14. Boilers' thermal production. 


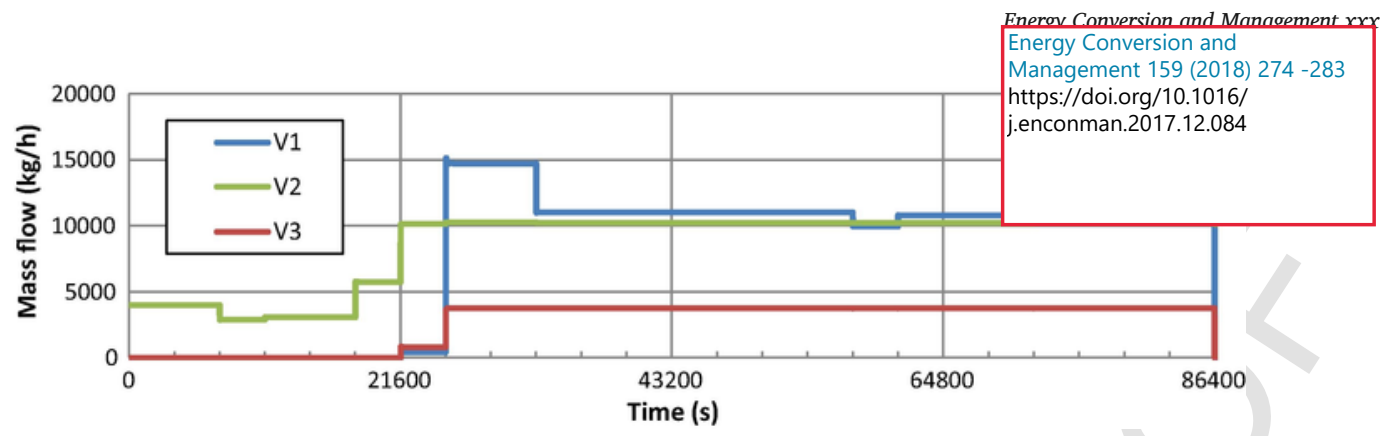

Fig. 15. Throttling valves, NG mass flows.

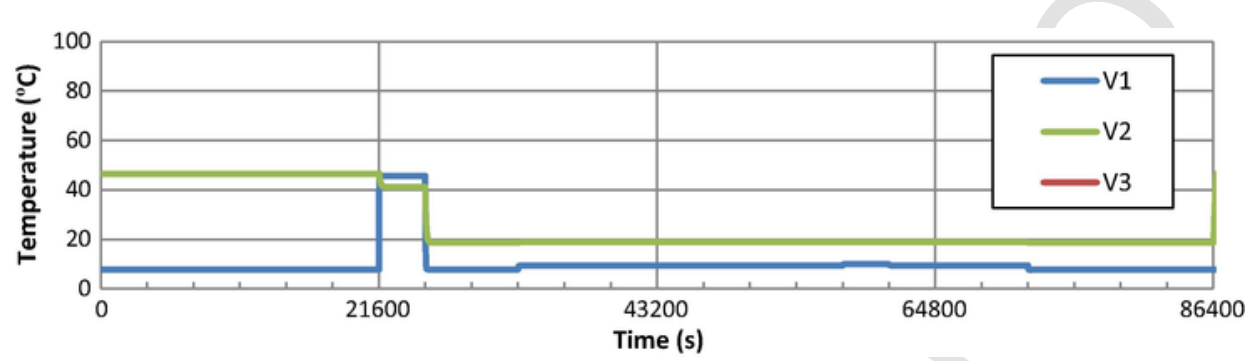

Fig. 16. Throttling valves, NG outlet temperatures.

for which the methane-hydrate formation occurs in the range $-2 /-5^{\circ} \mathrm{C}$. Only LTC was considered since that is certainly the most critical condition for methane hydrates formation. This configuration was analyzed for different operational conditions in order to estimate the minimum water-process-temperature set point before methane-hydrate formation might occur. More precisely, referring to Fig. 17 the entire dynamic simulation refers to a time length of about $33 \mathrm{~min}$ where the NG inlet temperature and the user demand were kept constant at $15^{\circ} \mathrm{C}$ and $20000 \mathrm{~kg} / \mathrm{h}$ respectively. The initial boilers' set points were fixed at $55^{\circ} \mathrm{C}$ and they were sequentially changed at minutes 1 and 10 to lower values of about $50{ }^{\circ} \mathrm{C}$ and $45^{\circ} \mathrm{C}$ respectively. After $20 \mathrm{~min}$, the boilers were shut off.

The temperature time history reported in Fig. 17 allows to analyze if and when methane hydrates form, and then to adopt a proper strategy in order to avoid this phenomenon. Of course, as clarified previously, this is only a specific example of a method, which can be widely applied to similar energy recovery systems in order to control and manage the possible undesired formation of a solid phase during the expansion process. Different inlet/outlet conditions, system configurations and operation strategies can be easily managed through the proposed methodology. Therefore, this approach can be easily replicated to guide design and management of integration of PRSs with low temperature heat sources aiming to energy recovery. In this sense, it is a valuable tool to sort out the main technical problem limiting the diffusion of this kind of technology.

\section{Discussion and applications}

Most plants, which generate the pressure drop from the national and transnational grid to the local ones, are provided with conventional boilers to prevent NG cooling below the temperature threshold, at which hydrate formation takes place. Currently, great interest is being devoted to the revamping of the PRS with TEs, in order to recover the energy otherwise dissipated in the throttling valves.

However, the ambitions of energy saving need to meet economical and technical requirements, which this study aims to address. A first technical issue analyzed here is the formation of methane hydrates. A second key-topic, overlapping the previous one, is integration of PRS recovery system with low temperature energy sources. For this development, the application of a two-stage expansion turns out to be definitely effective, so opening up to easier integration between gas and heating urban networks.

In the light of the method shown in the previous section and of the resulting outcomes, benefits coming from low-temperature pre-heating, evaluation of integrated system performance and control of methane hydrates are discussed and exemplified. With regard to this, it is important to notice that, despite its configuration complexity, the power produced by a double-stage expansion process is comparable with that produced by a single-stage one and that, in most operating conditions, the LTC gives only slighter reduction, if any. The analysis of the results, which are shown in the previous section, confirm the hypothesis of

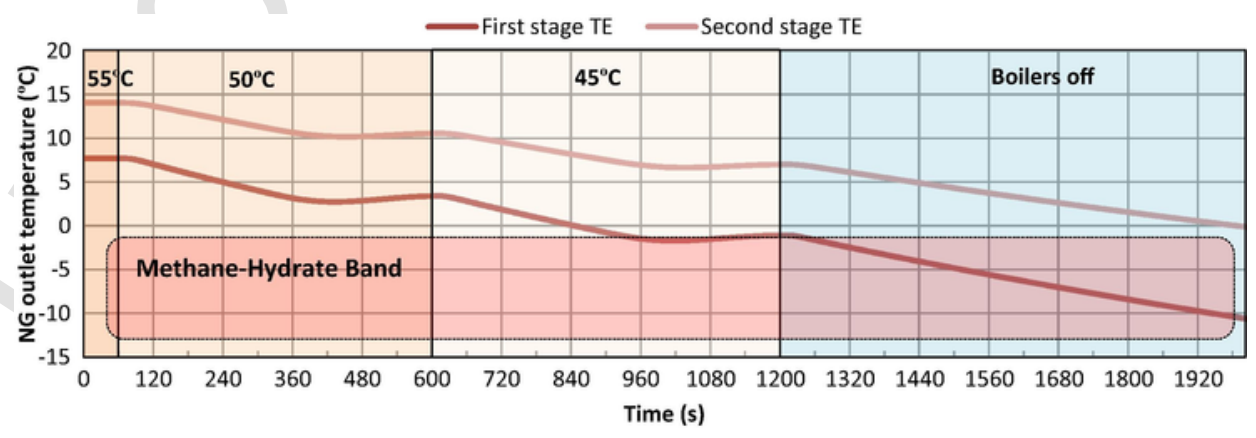

Fig. 17. TEs' NG outlet temperatures for different set points. 
gathering a considerable amount of work from a double-expansion process in a PRS.

\subsection{Advantages of low temperature pre-heating}

A set of interesting advantages is hidden behind the temperature reduction strategy in PRS (Fig. 18). These advantages are mutually connected and all of them gravitate towards the possibility of reducing carbon emissions in urban areas. In fact, first of all, reducing the temperature would open up the possibility of exploiting ever lower enthalpy heat sources and introduces even more efficient and renewable solutions as well. Apropos, it is possible to sort some pre-heating technologies in an approximate temperature-descending order: condensation boilers, CHP, high-temperature heat pumps and solar heaters. Moreover, integration with District Heating Networks (DHN) is facilitated and lower heat losses can be achieved. All these elements contribute to increasing the economic sustainability of this energy recovery technology and so its replicability.

PRS temperature reduction benefits not only consist of the implementation of more efficient primary energy-conversion or renewable components, since there are more advantages that it is important to highlight. In fact, the LTC is potentially characterized by a phenomenon of self-induced economic and financial sustainability. This means that, by reducing the temperature, we would also be able to integrate it with, for instance, 4th generation DHN [20] enabling economic sustainability due the added income generated by the thermal energy sold by the PRS. At this stage, it is worth recalling that, based on the au-

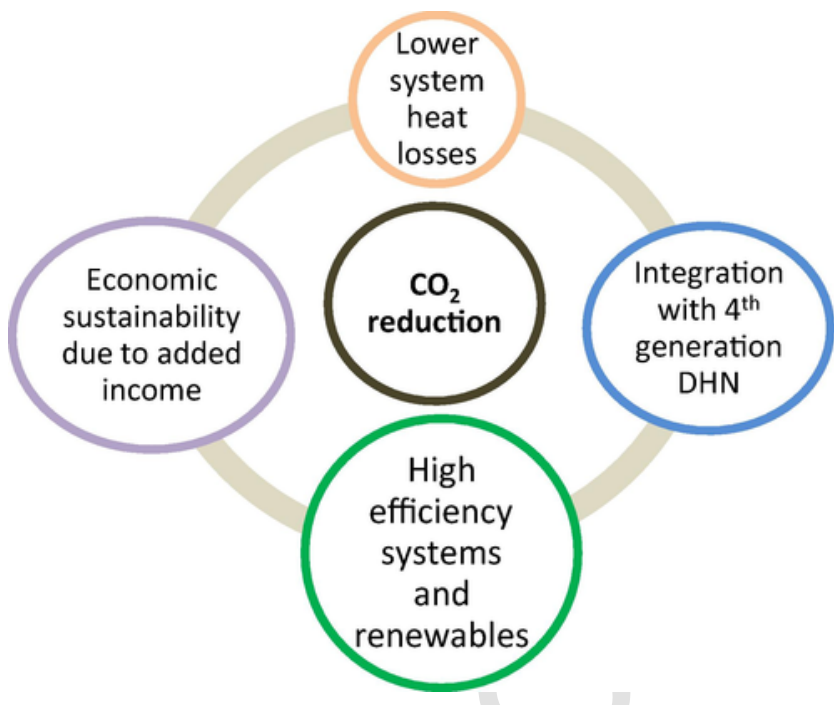

Fig. 18. Representation of low temperature configuration advantages. thors' experience, the initial investment price of the LTC might increase by about $30-40 \%$ compared to the HTC case. An effective economic analysis is nevertheless strongly influenced by the specific cost in installed $\mathrm{k} € / \mathrm{kW}$ of the selected machine, and this value is largely variable from one model to the other, depending on their efficiency and the technologies employed (e.g. [35-41]).

Also, with the proposed LTC it would be possible to reduce heat losses along pipelines when the recovery system is heat supplied by DHN. Lower delivery and return temperatures decrease the temperature along the heating grid pipelines and so the heat loss to the environment. For colder countries, where winter low outdoor temperatures boost the heat exchange with the external environment, this would lead to relevant energy saving. In a mirror way, it is possible to exploit existing DHN to pre-heat the PRS in an even more operative way as far as the recovery system temperature is low, so capitalizing on existing infrastructures with low cost pre-heating solutions.

A further related opportunity is integration with 4th generation DHN. The future evolution of district heating and cooling networks will be one of the key tools to reach zero $\mathrm{CO}_{2}$ footprint cities. This evolution will be based on the combination and on the integration of the actions for urban planning and management, together with the use of tools for decision-making support, BIM, as well as, the development of city energy mapping, of source and supply, with Geographical Information Systems (GIS).

For this reason, it is important to analyze the performance of the plants fed by a low temperature heat source. Comparing Figs. 5-10 one by one, which present the HTC performance, with the corresponding Figs. 11-16, which contain the LTC ones, it is possible to see that the novel configuration is able to operate correctly in the selected scenario. Thanks to this comparison, it is possible to conclude that the novel LTC, which preheats NG to $50-55^{\circ} \mathrm{C}$ only, properly matches the normal daily transient as well as the HTC.

\subsection{System performance assessment}

Performance analysis shows how, for the low temperature configuration, it is possible to achieve an average reduction of about $14 \%$ on the specific heat supply with respect to the high temperature system configuration, for a typical winter day. Fig. 19 presents the dynamic variation of the thermal energy saving for the LTC in comparison with HTC. For the same NG-flow scenario, reproducing a typical winter flow rate over a day, Fig. 20 shows a comparison between the ratios of the specific heat consumption and power outputs for low and high temperature configurations respectively: unlike the HTC, the LTC enables a higher energy ratio. However, it must be underlined that, at a given NG mass flow rate, the global efficiency is linked to the complex interaction of the following main parameters: the TE's efficiency, which determinates outgoing gas temperature and the power output, the NG

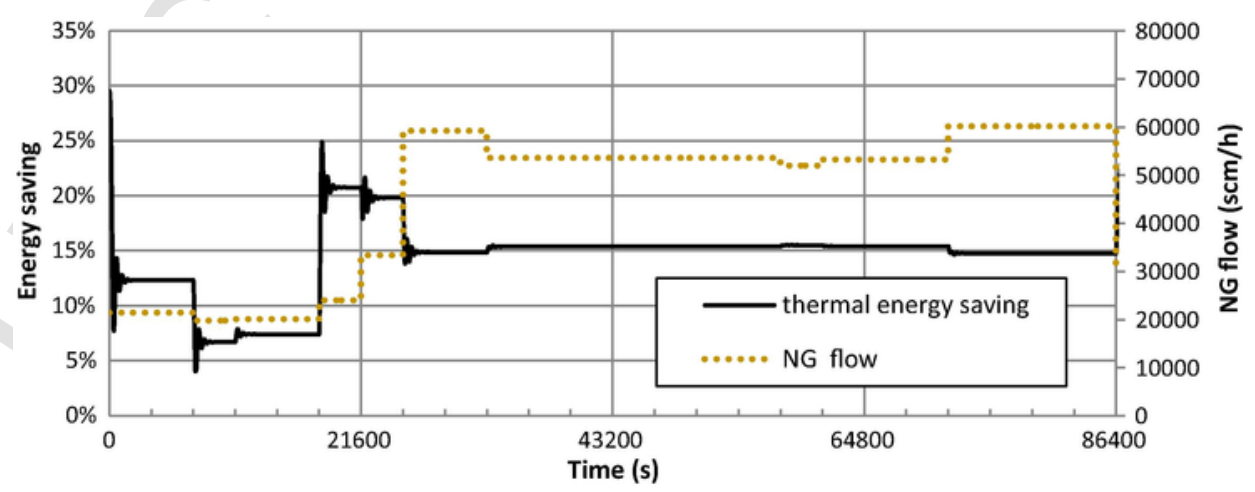

Fig. 19. Percentage thermal need reduction between systems. 


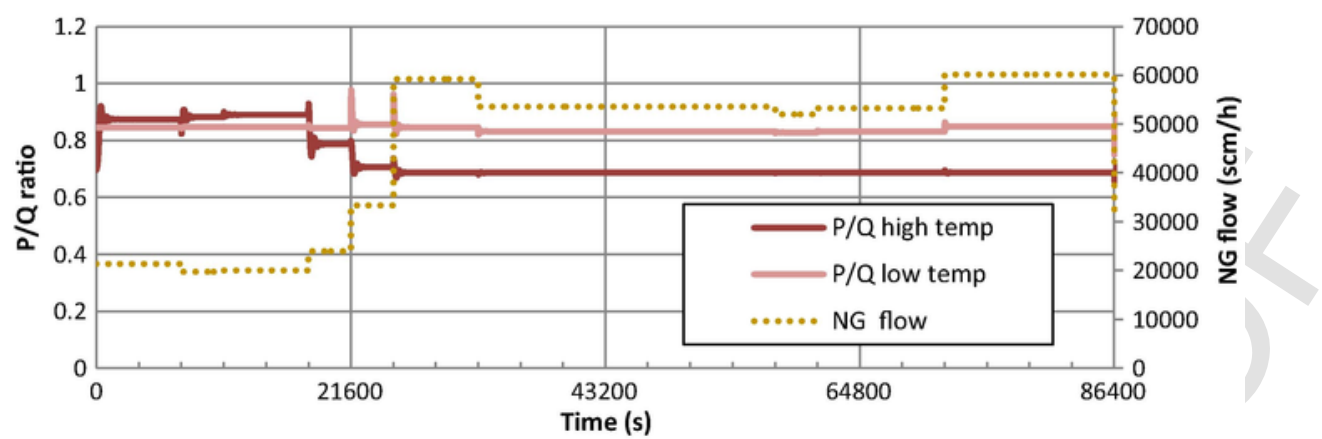

Fig. 20. Energy-ratio comparison between two system configurations.

specific volume, which determinates the pressure drop, the dynamic behavior of the valves opening, which generates different thermal need and, finally, the boilers efficiency.

Obviously, a crucial aspect is also related to the control of the whole system. As demonstrated in [16], it is possible to achieve a $17 \%$ energy saving by implementing an appropriate control in this type of system. Moreover, the thermal integration with external users, would require even more attention to this issue since, more efficient primary energy conversion could be achieved by implementing appropriate optimization algorithms. However, typical city-gate-PRS-NG-load profiles have a natural matching with thermal and electrical ones making integration even easier and, for well-designed systems, the implementation of thermal or electrical storages might be avoided.

\subsection{Control of methane hydrate formation}

The dynamic model of the LTC is able to assess the dynamic behavior of the plant in case of fault of the heat source. The large thermal capacity of the components of HTC and the value of the temperature of their thermal supplier give rise to a long transient that can be easily managed by the operators. In this framework, it is interesting to study the dynamic behavior, in case of fault, of the LTC because, due to its lower-temperature set point, it could generate shorter transients that might lead, in too short a time, to unsafe conditions. For this reason, a dynamic simulation of the LTC, in case of fault of the thermal supplier, was carried out and the results are reported in Fig. 17. It is possible to see that the time which it takes to reach the hazardous conditions of hydrate formations, is more than $15 \mathrm{~min}$. In fact, the temperature at the first stage outlet, that is the lower one, drops below $-2{ }^{\circ} \mathrm{C}$ about $1000 \mathrm{~s}$ after the beginning of the event.

This is a further assessment of LTC operation, because the existing control system can operatively manage such a long-time response, in order to avoid hazardous conditions that would easily lead to expensive system damage after a few minutes. Similar simulations, developed for LTC at diverse operating conditions and not reported here for brevity, confirm the possibility of activating the operators, where available, or of putting into effect a redundant TE-supervision system for isolated and unmanned stations, where the personnel time-to-intervention is longer than the abovementioned threshold.

\section{Conclusions}

There are many advantages in reducing the process temperature of NG pressure reduction stations with energy recovery. The possibility of exploiting low enthalpy heat sources (waste heat), of implementing more efficient system configurations (condensing boilers, geothermal heat pumps etc.), and of integrating 4th generation district heating networks are mutually connected benefits. They result in larger energy saving and carbon emissions reduction. All these factors led the authors to analyze the possibility of reducing the recovery process temperature in PRS, particularly by considering a double-stage expansion process i.e. two turbo-expanders in series.

The conducted study confirmed feasibility and effectiveness of that configuration. From a technical point of view, the operational functionality was tested and analyzed. The novel LTC, which preheats NG to $50-55^{\circ} \mathrm{C}$ only, properly matches the normal daily transient as well as the HTC. Integration with existing district heating networks is facilitated, as well as the chance to recover low temperature waste heat is enhanced. Sustainable urban planning can find in this innovative set up a tool for grids integration and smart energy management, up to the integration with 4th generation DHN. Meanwhile, economic sustainability and replicability of energy recovery from PRS are fostered. Existing infrastructures exploitation, with the cut of investment costs, and heat losses reduction improve affordability. In fact, despite higher initial costs, waste energy profiteering and better recovery performance enable the possibility of PRS-retrofit investments and foster the technology dissemination.

As commonly known, during NG preheating water process temperature is normally set to $85^{\circ} \mathrm{C}$. With the proposed novel configuration, the temperature can be reduced to $55^{\circ} \mathrm{C}$. However, working with these conditions makes the risk of methane-hydrate formation even higher, since it becomes easier to fall into the hydrate zone in a shorter time. For this purpose, in this study an accurate transient analysis was carried out for a typical winter scenario, which is the most suitable for this purpose. The results of the analysis demonstrate that the proposed novel configuration does not lead to hazardous system operations, i.e. the risk of methane-hydrate formation is warded off under normal operating conditions. Moreover, extreme conditions were analyzed, i.e. the system behavior in case of thermal supply and turbo-expander supervision fault was studied. Considering the low temperature configuration, we calculated the time-to-hydrates including system thermal inertia. For the reference conditions, starting from the initial set point of $55^{\circ} \mathrm{C}$, if a fault occurs, the system would fall into the hydrate zone within $15 \mathrm{~min}$. This confirms the feasibility of LTC operation, because current control systems can operatively manage such a long-time response in order to avoid hazardous conditions.

Finally, the energy performance of HT and LT configurations were compared. In this case, the results show that LTC can achieve higher energy performance, reaching an added energy saving of about $14 \%$ in comparison with high temperature configuration for typical winter operating conditions. The role of appropriate optimization algorithms revealed to be actually relevant for a full capitalization of waste energy harvesting and low temperature heat. Although the global energy efficiency mainly depends on - TE's performance, NG specific volume and valves dynamic behavior, through a smart system control it is possible to improve the energy recovery. Besides, typical city-gate-PRS-NG-load profiles have a natural matching with thermal and electrical ones and make integration even easier, also avoiding the need of thermal or electrical storage. 
Concluding, the novel proposed system configuration has many advantages in terms of opportunity to exploit low enthalpy heat sources, highly efficient primary-conversion-technology utilizations and integration with renewable sources. Moreover, the novel low temperature configuration, with an appropriate control logic, could easily achieve higher energy performance with respect to the high temperature one, increasing carbon emission reduction in urban areas and keeping system operations safe.

\section{Acknowledgments}

This work was developed in the framework of the collaborative project CELSIUS (Combined Efficient Large-Scale Integrated Urban Systems). This project has received funding from the European Union's Seventh Framework Programme for research, technological development and demonstration under grant agreement № 314441.

\section{References}

[1] CELSIUS project. Available online: < http://celsiuscity.eu/> [accessed: 14/07/ 2017].

[2] ENEGAS. Available online: < http://www.enegas.es > [accessed on 14/07/2017]

[3] GAS CONNECT AUSTRIA. Available online: < http://www.gasconnect.at > [accessed on 08/03/2017].

[4] Gas in Denmark. Plan for security in natural gas supply; 2009. Available online: < http://www.energinet.dk/DA/Sider/default.aspx/ > [accessed on 08/03/2017]

[5] M. Alparslan, O. Ozgener, L. Ozgener, Energy and exergy analysis of electricity generation from natural gas pressure reducing stations, Energy Convers Manag 93 (2015) 109-120.

[6] Borelli D, Devia F, Lo Cascio E, Schenone C, Spoladore A. Combined production and conversion of energy in an urban integrated system. Energies; 2016.

[7] Mansoor SA, Mansoor A. Power generation opportunities in Bangladesh from gas pressure reducing stations. In: 3rd International conference on electrical \& computer engineering, ICECE; 2004

[8] W. Kostowski, The possibility of energy generation within the conventional natura gas transport system, Strojarstvo 52 (4) (2010) 429-440.

[9] M. Farzaneh-Gord, M. Deymi-Dashtebayaz, Recoverable energy in natural gas pressure drop stations: a case study of the khangiran gas refinery, Energy Explor Exploit 26 (2) (2008) 71-82.

[10] Hammerschmidt EG, Natural T, Company G. Gas hydrates in natural gas transmission lines. Ind Eng Chem 1934;1(4).

[11] C.A. Koh, R.E. Westacott, W. Zhang, K. Hirachand, J.L. Creek, A.K. Soper, Mechanisms of gas hydrate formation and inhibition, Fluid Phase Equilib 197 (2002) 143-151.

[12] E. Ashouri, F. Veysi, E. Shojaeizadeh, M. Asadi, The minimum gas temperature at the inlet of regulators in natural gas pressure reduction stations (CGS) for energy saving in water bath heaters, J Nat Gas Sci Eng 21 (2014) 230-240.

[13] Khamehchi E, Shamohammadi E, Yousefi SH. Predicting the hydrate formation temperature by a new correlation and neural network. Gas Process J 2013;1(Feb.):41-50.

[14] Farzaneh-kord V, Khoshnevis AB, Arabkoohsar A, Deymi-dashtebayaz M. De fining a technical criterion for economic justification of employing CHP technology in city gate stations 2016;111:389-401.

[15] A. Arabkoohsar, Z. Gharahchomaghloo, M. Farzaneh-gord, R.N.N. Koury, An energetic and economic analysis of power productive gas expansion stations for employing combined heat and power, Energy 133 (2017) 737-748.

[16] E. Lo Cascio, D. Borelli, F. Devia, C. Schenone, Future distributed generation: an operational multi-objective optimization model for integrated small scale urban electrical, thermal and gas grids, Energy Convers Manag 143 (2017) 348-359.
[17] SNAM. Available online < http://www.snam.it/> [accessed 14/07/2017]

[18] S.H. Chae, S.H. Kim, S. Yoon, S. Park, Optimization of a waste heat utilization network in an eco-industrial park, Appl Energy 87 (6) (2010) 1978-1988.

[19] Marguerite C, Schmidt R, Garcia NP. Concept development of an industrial waste heat based micro DH network. CISBAT 2015;597-602.

[20] H. Lund, S. Werner, R. Wiltshire, S. Svendsen, J. Eric, F. Hvelplund, et al., 4th Generation District Heating (4GDH) Integrating smart thermal grids into future sustainable energy systems, Energy 68 (2014) 1-11.

[21] Arabkoohsar A, Andresen GB. A smart combination of a solar assisted absorption chiller and a power productive gas expansion unit for cogeneration of power and cooling. Renew Energy; 2017.

[22] M. Farzaneh-gord, A. Arabkoohsar, M.D. Dasht-bayaz, L. Machado, Energy and exergy analysis of natural gas pressure reduction points equipped with solar heat and controllable heaters, Renew Energy 72 (2014) 258-270.

[23] M. Farzaneh-gord, R. Ghezelbash, M. Sadi, A. Jabari, Integration of vertical ground-coupled heat pump into a conventional natural gas pressure drop station: energy, economic and $\mathrm{CO}_{2}$ emission assessment, Energy 112 (2016) 998-1014.

[24] M. Motiee, Estimate possibility of hydrates, Hydrocarbon Process 70 (7) (1991) 98-99.

[25] B.F. Towler, S. Mokhatab, Quicky estimate hydrocarbon formation conditions in natural gases, Hydrocarbon Process 84 (2005) 61-62.

[26] Arthur J. Kidnay, William R. Parrish, Daniel G. McCartney, Fundamentals of natural gas processing, 218, CRC Press, 2011.

[27] E. Dendy Sloan Jr., Carolyn Koh, Clathrate hydrates of natural gases, CRC Press, 2007.

[28] W.J. Kostowski, S. Usón, Thermoeconomic assessment of a natural gas expansion system integrated with a co-generation unit, Appl Energy 101 (2013) 58-66.

[29] W.J. Kostowski, S. Usón, W. Stanek, P. Bargiel, Thermoecological cost of electricity production in the natural gas pressure reduction process, Energy 76 (2014) 10-18.

[30] W.J. Kostowski, J. Kalina, P. Bargiel, P. Szufleński, Energy and exergy recovery in a natural gas compressor station - a technical and economic analysis, Energy Convers Manage 104 (2015) 17-31.

[31] Stanek W, Gazda W, Kostowski W, Usón S. Exergo-ecological assessment of multi-generation energy systems. In: Thermodynamics for sustainable management of natural resources. Springer International Publishing; 2017. p. 405-42.

[32] Honeywell Unisim ${ }^{\circledR}$ Design Suite. Available online: < https://www. honeywellprocess.com $>$ [accessed on 08/03/2017].

[33] UniSim ${ }^{\circledR}$ design dynamic modeling reference guide R450 release. Honeywell, London, Ontario, Canada; 2016

[34] Pietro Fiorentini. Available online: < https://www.fiorentini.com/it/ > [accessed 14/07/2017].

[35] G.E. Zarnitskii, L.A. Repin, V.A. Elema, L.V. Chernina, R.A. Chernin, Utilization of screw-type expanders in power-and-technology plants. [ISPOL'ZOVANIE VINTOVYKH RASCHIRITEL'NYKH MASHIN V ENERGOTEKHNOLOGICHESKIKH USTANOVKAKH.], Izvestiya Vysshikh Uchebnykh Zavedenij i Energeticheskikh Ob"edinenij Sng. Energetika 17 (12) (1974) 73-77.

[36] Braekow D, Fink M, Tanner N. In the power station in Schwarza (Thuringia, Germany) natural gas works even before getting burned in turbines and boilers [Im IKW Schwarza leistet Erdgas schon vor der Verbrennung Arbeit]. Energieanwendung und Energietechnik 1994;43(6):229-33

[37] A.I. Prilutskii, Use of piston expanders in plants utilizing eneroy of compressed natural gas, Chem Pet Eng 44 (3-4) (2008) 149-156.

[38] M. Imran, M. Usman, B.-S. Park, D.-H. Lee, Volumetric expanders for low grade heat and waste heat recovery applications, Renew Sustain Energy Rev 57 (2016) 1090-1109.

[39] Kolasiński P, Pomorski M, Blasiak P, Rak J. Use of rolling piston expanders for en ergy regeneration in natural gas pressure reduction stations-selected thermodynamic issues. Appl Sci (Switzerland) 2017;7(6), art. No 535.

[40] Barbarelli S, Florio G, Scornaienchi NM. Theoretical and experimental analysis of a new compressible flow small power turbine prototype. Int J Heat Technol 2017;35(1).

[41] Li G, Wu Y, Zhang Y, Zhi R, Wang J, Ma C. Performance study on a single-screw expander for a small-scale pressure recovery system. Energies 2017;10(1), art. No 